\title{
O PODER DAS SIMULAÇÕES NO ENSINO DE HIDRÁULICA
}

\author{
Oscar Eduardo Patrón Guillermo* \\ Liane Margarida Rockenbach Tarouco** \\ Luiz Augusto Magalhães Endres***
}

\section{Resumo}

Este trabalho tem como objetivo mostrar a necessidade de desenvolver novas ferramentas tecnológicas, para o ensino de hidráulica para engenheiros, mais precisamente a utilização de simuladores virtuais, das práticas em laboratórios de hidráulica; destacar as vantagens das simulações como complemento à aula tradicional expositiva, assim como o ganho no processo de ensino e aprendizagem dos alunos, expostos a este tipo de material instrucional. Para isto foram elaborados 3 simuladores utilizando o software Flash MX da Macromedia, representando 3 práticas laboratoriais de hidráulica. Duas turmas do curso de Engenharia da UFRGS, utilizaram estes simuladores. Pode-se afirmar que os simuladores podem ser ótimas ferramentas no auxílio à aula convencional e que na área da Engenharia devería-se investir tempo e recursos para implementar materiais instrucionais deste tipo, para obter uma melhor qualidade no ensino, assim como para obter uma melhor compreensão de alguns fenômenos físicos ocorridos nestas práticas, principalmente em instituições que não disponham de laboratórios de hidráulica.

Palavras-chave: simulações, ensino em hidráulica, simulações na engenharia.

\section{THE POWER OF THE SIMULATIONS IN THE HYDRAULICS TEACHING}

*Abstract

This paper's objective is to show the need for developing new technological tools to teach hydraulics for engineers, more precisely the use of virtual simulations of the practices in hydraulic laboratories, and to highlight the advantages of simulations to complement traditional lectures, as well as the benefits in the process of teaching and learning by students exposed to this type of instructional material. To accomplish this, 3 simulators were created using the software Flash MX of Macromedia, representing 3 practices in a hydraulic laboratory. Two groups of students from the Engineering course at UFRGS used these simulators. It was shown that the simulators can be useful tools as aid to conventional lectures, and that in the area of Engineering, time and money should be invested in order to implement instructional materials of this type, aiming at betterquality teaching and a better understanding of the physical phenomena involved in laboratory practices, mainly in institutions that do not have hydraulic laboratories.

Key Words : simulations, teaching in hydraulics, simulations in engineering.

\footnotetext{
* Gerente de Rede IPH - Eng. Especialista em Informática na Educação - CINTED/UFRGS. oepg@iph.ufrgs.br

** Diretora Cinted- Doutorado em Engenharia Elétrica-Sistemas Digitais - USP. liane@penta.ufrgs.br

*** Prof. DHH/IPH - Doutorado em Engenharia Mecânica - UFRGS. endres@iph.ufrgs.br 


\section{INTRODUÇÃO}

A utilização de software educativo está sendo muito explorada no processo de ensino e aprendizagem de engenharia, trazendo com isto a necessidade de estudos para o seu desenvolvimento.

A proposta deste trabalho foi de proporcionar aos alunos da disciplina Mecânica dos Fluidos II - IPH 01107 da UFRGS, turma B, semestre 2004/02, além da realização normal dos experimentos práticos previstos em laboratório de hidráulica, o uso de simulações computacionais destes experimentos, tentando mostrar a necessidade de desenvolver novas ferramentas tecnológicas, para o ensino de hidráulica para engenheiros, mais precisamente a utilização de simuladores virtuais, das práticas em laboratórios de hidráulica; destacar suas vantagens como complemento à aula tradicional expositiva, assim como o ganho no processo de ensino aprendizagem dos alunos, expostos a este tipo de material instrucional.

O desenvolvimento de trabalhos de laboratório de hidráulica, na maneira como é normalmente efetuado e que já fornece bons resultados, exige dos alunos, além da absorção de conhecimentos em sala de aula, que leiam previamente um texto especialmente preparado para reforçar os conteúdos e orientar a prática a ser executada no laboratório. A realização prévia de simulações com auxílio da informática desses experimentos, em muito semelhantes às que serão posteriormente desenvolvidas na realidade do laboratório, permite unir os conteúdos vistos em aula, a leitura do texto (que acompanha o próprio experimento) e o interesse peculiar dos estudantes pelo uso do computador como ferramenta de trabalho.

Embora as simulações desenvolvidas, no caso desta disciplina, não tenham o objetivo de substituir as práticas no laboratório de hidráulica, é possível supor que, após corrigidos pequenos problemas de forma e conteúdo no primeiro conjunto de resultados obtidos, esta ferramenta possa ser oferecida a outras pessoas e/ou instituições de ensino interessadas, principalmente para aquelas que não disponham do laboratório de hidráulica físico para trabalhar mas que terão, com o uso do meio computacional e as simulações já otimizadas, possibilidade de visualização de fenômenos em muito facilitada. Vemos aqui então, o papel da instituição de ensino sendo cumprido com a universalização de conhecimentos, e de proporcionar meios e incentivar os interessados a usufruir das novas ferramentas tecnológicas aplicadas ao ensino.

\section{MOTIVAÇÃO DO TRABALHO}

As limitações do ensino público, principalmente financeiras, têm feito com que seja necessário enfrentar alguns problemas que acabam por prejudicar não só o ensino, mas também, o aprendizado de alunos universitários. Uma destas limitações é a falta de recursos para a aquisição e manutenção de laboratórios experimentais, utilizados na fixação dos conceitos teóricos, que na área da Engenharia é muito comum. Este fato tem dificultado o contato dos alunos com as práticas de laboratório já que, segundo Kleinhappel et al.(2004), os laboratórios experimentais ainda em funcionamento, da área de hidráulica e mecânica dos fluídos, remanescentes de épocas de maiores recursos destinados à educação, encontram-se espalhados entre algumas universidades.

Kleinhappel apud Kiernan (1997), cita que iniciativas desta natureza podem estreitar a distância entre os estudantes de engenharia de escolas relativamente ricas e que podem custear facilidades laboratoriais abrangentes a aquelas instituições que contam com menores recursos e faculdades comunitárias, que não podem oferecer facilidades laboratoriais abrangentes. Os programas de simulação propiciam aos estudantes, a interação com modelos e processos complexos de forma controlada 
(muitas vezes inviável em escala real), sem riscos que envolvam periculosidade ou gastos proibitivos, já que estes simuladores envolvem a criação de modelos dinâmicos e simplificados do mundo real. Sendo assim, o potencial educacional deste tipo de ferramenta é muito superior ao dos programas tradicionais.

Os autores Toval e Flores (1987) relatam que as simulações podem permitir aos alunos construírem, em suas mentes, modelos de sistemas físicos que, muitas vezes, não conseguem desenvolver de forma adequada apenas com a escuta do professor ou a leitura de manuais, recorrendo à memorização. A observação de simulações bem concebidas pode ajudar o aluno a mentalizar modelos melhor estruturados.

As simulações podem despertar ou aumentar o interesse dos alunos já que, com o fato de poderem controlar determinadas simulações, é induzida uma aprendizagem mais fácil e rápida, o aluno pode ver como se altera o comportamento do modelo em uma variedade de situações e condições.

Segundo Otoni (2004), em seu trabalho "O uso de Simuladores e as Estruturas Cognitivas", a simulação dá vida às aulas, fornecendo ferramentas com as quais os estudantes apreciam trabalhar, pois desta maneira aprendem fazendo. Trata-se de uma ferramenta de estudo interativa que ajuda a construir e trabalhar conceitos. $\mathrm{O}$ mesmo autor relata que em seus experimentos é possível dar acesso virtual a todos os componentes necessários para criar projetos de qualquer complexidade. Ao contrário dos equipamentos didáticos tradicionais, normalmente não é necessária a aquisição de componentes adicionais como, por exemplo, no caso de uma simulação mecânica real, a compra de um componente de maior custo.

Uma das vantagens do uso de softwares simuladores consiste na economia de tempo e dinheiro, pois não é preciso contar com laboratórios, equipamentos e técnicos, além de não ser preciso contratar ou treinar pessoal específico para a operação desses laboratórios. Também se dispensam a checagem e manutenção de equipamentos e evitam-se os possíveis erros de suas montagens e operações. Em contrapartida perde-se todo o conhecimento específico que decorre da inerente aleatoriedade associada aos fenômenos físicos, marcadamente em hidráulica e mecânica dos fluidos, e os relacionados a esses procedimentos "dispensáveis", como o conhecimento sobre a montagem dos equipamentos e os cuidados de operação. Daí vem a importância do uso racional dos simuladores conforme os objetivos que se pretendam obter com seu uso. Através da simulação não é possível obter, de imediato, resultados que levem à otimização de um objetivo desejado. Entretanto, é possível simular, por meio do modelo, uma série de experimentos em diferentes condições e, posteriormente, escolher a condição cujos resultados sejam mais aceitáveis (Ehrlich, 1976).

\section{CONCEITUAÇÃO}

Um simulador funciona como um dispositivo que reproduz virtualmente uma situação real (ou que poderia ser real) e dessa forma nos permite "experimentar" os efeitos de um determinado procedimento sem que a situação real esteja de fato ocorrendo. As simulações podem ser vistas como representações ou modelagens de objetos específicos, reais ou imaginados, de sistemas ou fenômenos. Elas podem ser bastante úteis, particularmente quando a experiência original for impossível de ser reproduzida pelos estudantes.

A simulação é um recurso de aprendizagem que permite ao estudante observar o comportamento de um determinado sistema através de um modelo do mesmo, ou seja, de uma representação matemática, gráfica ou simbólica de um fenômeno. Neste contexto, as simulações podem exercer um papel minimizador do problema existente 
devido à falta de estrutura de parte das Faculdades de Engenharia do Brasil, em termos de laboratórios e equipamentos, para os cursos de graduação.

Segundo Vance e Bosworth (2003), uma simulação é um ambiente realístico no qual os estudantes executam uma tarefa significativa e experimentam suas conseqüências, avaliando o comportamento deles/delas naquele ambiente. Numa simulação, os estudantes têm, freqüentemente, ferramentas de ajuda e apoio embutidas na própria simulação, de como utilizar estas próprias ferramentas para realizar as tarefas. Estes autores ainda destacam que as simulações podem trazer alguns benefícios na aprendizagem dos alunos, tais como:

- Uma aprendizagem mais profunda, onde os estudantes simulam um problema complexo, resolvendo estratégias e integrando habilidades.

- Ambiente de baixo risco, pois os estudantes adquirem experiência com situações difíceis sem consequiências caras ou irreversíveis, de modelos reais de alto custo.

- Os estudantes são emocionalmente mais envolvidos quando mergulham em uma experiência real do mundo que o cerca. Simulações trazem experiências de aprendizagem efetivas porque servem como uma ponte do ambiente de aprendizagem para realidade.

\section{MATERIAL E MÉTODOS}

As simulações descritas neste trabalho, foram desenvolvidas utilizando o software Flash MX, da Macromedia, e aplicadas a uma turma da disciplina regular do curso de Engenharia da UFRGS - Mecânica dos Fluidos II - IPH 01107, turma B, semestre 2004/02; esta disciplina fornece conteúdos básicos para o estudo da Hidráulica, Fenômenos de Transporte, Hidrologia, Máquinas Hidráulicas, Saneamento e Gerenciamento de Recursos Hídricos.

Para isto foram elaborados 3 simuladores, representando as práticas laboratoriais de hidráulica: Velocidade em Canal, Esvaziamento de Reservatório e Aferição de Venturi. Estas aulas no laboratório de hidráulica, funcionam como uma aplicação prática do conteúdo ministrado na disciplina e vão de encontro ao objetivo da mesma, que são os de fornecer aos alunos os conhecimentos básicos das propriedades dos fluidos, dos esforços mecânicos e das leis de conservação de massa, quantidade de movimento e energia, além de apresentar noções e conceitos básicos do escoamento real.

Flash é o padrão da Web para animação e imagens vetoriais. Com o Flash, podese rapidamente dar uma visão animada às páginas da Web, com imagens animadas e efeitos de texto; também permite incluir uma interatividade sofisticada aos sites sem programação de scripts complicada, para isto utiliza o ActionScript, que é a linguagem de criação de scripts do Macromedia Flash MX. Quando aliado ao projeto e desenvolvimento de material educacional, desde objetos de aprendizagem, simulações, a jogos educacionais, o Flash MX tem se mostrado um dos softwares mais completos e simples de ser usado, mesmo por aqueles que não têm experiência com linguagens de programação, sendo atualmente a ferramenta padrão no mercado para criação de tais aplicativos.

O ambiente de criação do Flash proporciona um conjunto completo de ferramentas para a construção de animações prontas para a Web. As ferramentas de desenho e texto permitem criar imagens e texto a partir do zero. Após criar um filme completo no Flash, pode-se exportá-lo para o formato de arquivo compactado .swf e adicionar o filme a uma página da Web, ou até mesmo criando arquivos executáveis, 
como é o caso das simulações abordadas neste artigo, podendo assim executa-las independentemente em qualquer computador.

Todas as simulações deste trabalho, seguem um padrão de layout modular, onde cada uma delas tem os seguintes componentes: Tela principal - área ou tela inicial onde são mostrados os componentes do experimento , Seção Calculadora - calculadora básica para cálculos necessários, Seção Vídeos - contendo vídeos do experimento em questão e do laboratório de hidráulica, Seção Fotos - contendo fotos dos componentes do experimento, Seção Testes e Perguntas - onde permite responder uma série de questões relacionadas ao experimento, Seção Apostila - contendo um arquivo no formato do Adobe Acrobat (*.pdf) com a apostila da aula prática, Seção Bibliografia - com a relação de bibliografia recomendada e o Experimento propriamente dito - ou seja, a simulação da prática laboratorial.

A representação dos diversos experimentos, que são na realidade a própria simulação, foram obtidos através de algumas simplificações das equações que regem o comportamento dos fluídos, descritas nas respectivas apostilas de cada experimento laboratorial.

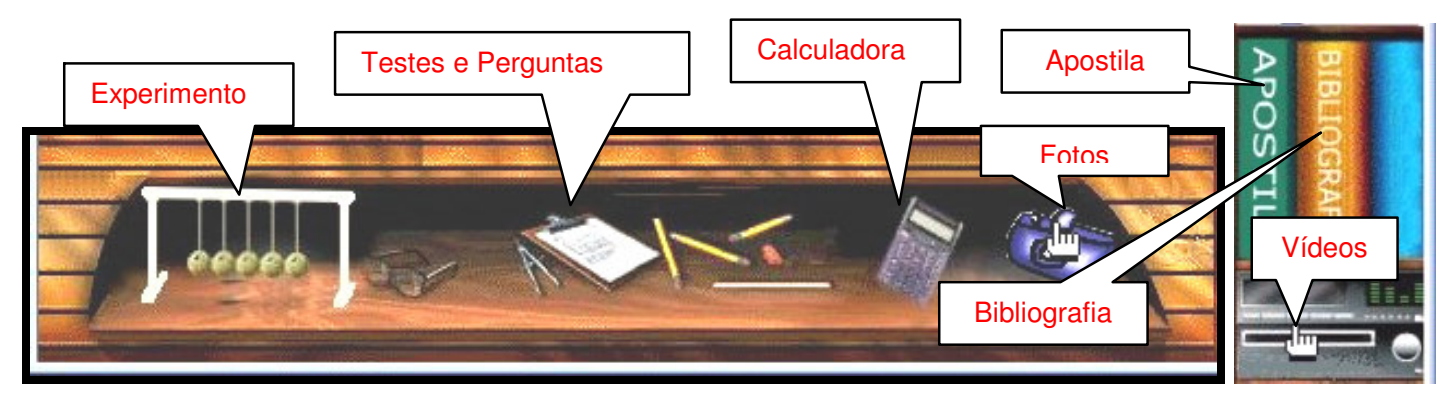

Figura 1. Menu padrão de navegação das simulações e suas seções

A turma foi dividida em 2 grupos, definidos pelo critério de ordem de chegada dos alunos, sendo que aproximadamente a primeira metade da turma que chegava ao laboratório de hidráulica, era direcionada para o laboratório de informática, desta maneira, estes alunos realizariam antes as simulações, e o restante da turma veria diretamente a prática real, no laboratório de hidráulica, assim formaram-se 2 grupos com 12 e 17 alunos cada um, sendo que o grupo de 12 alunos foi o que realizou primeiramente a prática a depois as simulações, chamado de grupo Hidra-Inf, e o grupo de 17 alunos, realizou primeiro as simulações e depois as práticas reais, chamado de grupo Inf-Hidra. $\mathrm{Na}$ aula seguinte, ocorreu a inversão, e os alunos que inicialmente realizaram as simulações, foram para o laboratório de hidráulica, sendo que os que tinham realizado a prática real, conheceram as simulações na sala de aula informatizada.

Os alunos também tiveram como material de apoio, a disponibilidade de uma página na Internet, localizada em http://galileu.iph.ufrgs.br/iph107simula , neste página Web encontram-se as simulações, apostilas e os vídeos das respectivas práticas laboratoriais, propiciando desta maneira, o acesso a estes recursos da casa dos próprios alunos, ou qualquer ouro lugar com conexão à Internet e a qualquer momento, podendo repetir e rever as simulações quantas vezes forem necessárias, podendo haver assim um maior entendimento dos fenômenos ocorridos durante a experimentação. 


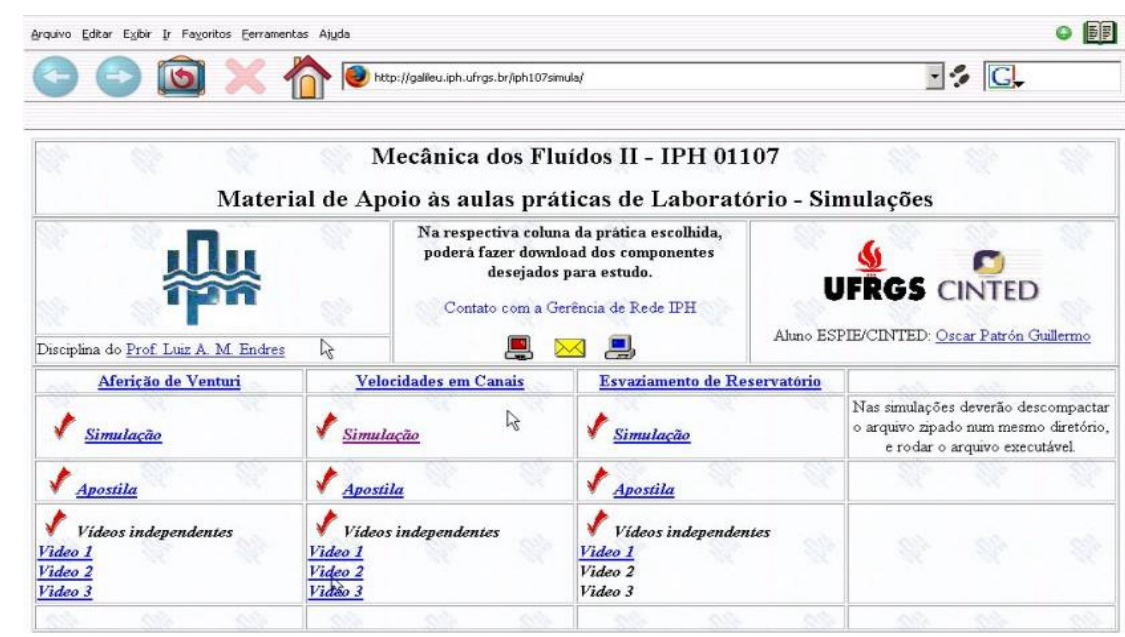

Figura 2. Página na Internet, com o material de apoio à aula presencial

Após todos terem efetuado as aulas práticas (Laboratório de Hidráulica e Sala Informatizada com os simuladores), os alunos responderam a um questionário de avaliação do material instrucional, composto de 30 perguntas, das quais parte delas são avaliadas neste artigo.

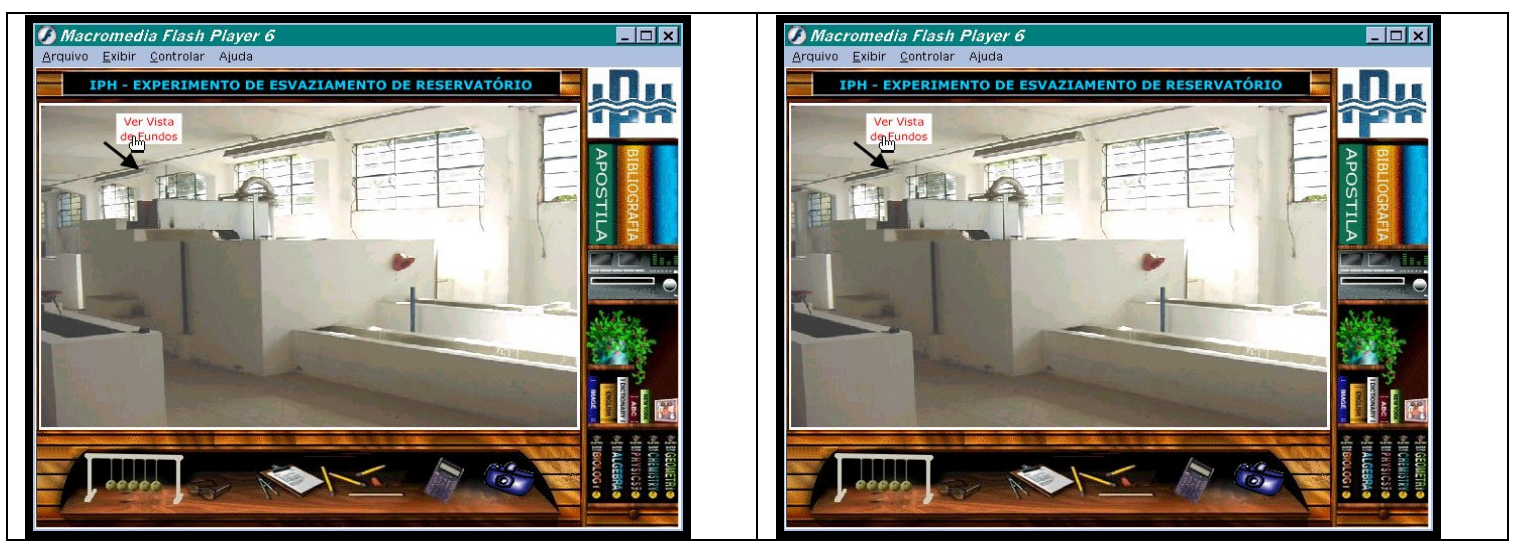

Figura 3. Simuladores das práticas de Esvaziamento de Reservatório e Velocidades em canais

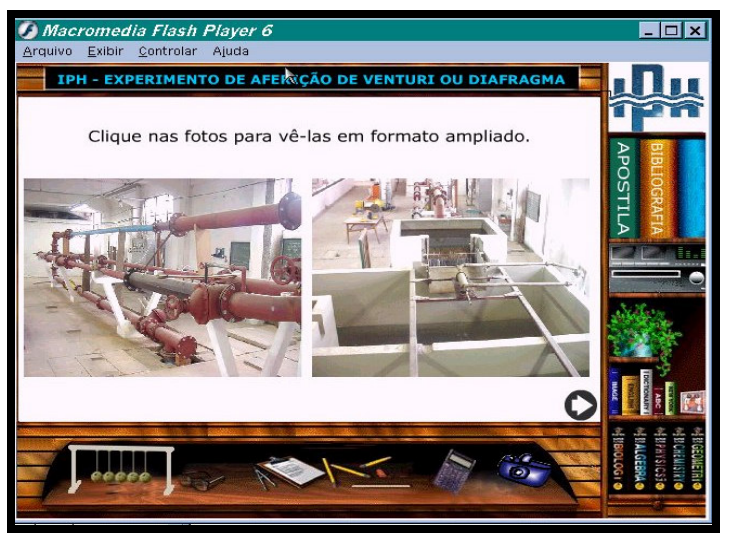

Figura 4. Simulador que representa a prática de Aferição de Venturi 


\section{RESULTADOS OBTIDOS}

Os resultados das respostas dos alunos, são analisados em termos percentuais, porém são apresentados também em relação ao número de alunos que responderam às opções fornecidas. A turma Hidra-inf estava composta de 12 alunos e a turma Inf-Hidra era composta de 17 alunos.

Foi calculado o percentual de respostas dadas a cada opção, em relação ao número de alunos de cada turma, e após, apresentado em termos médios das 2 turmas.

Tabela 1. Importância do apoio multimídia na hidráulica Quão importante para você é ser exposto a uma ferramenta de apoio multimídia como um simulador, na área de hidráulica?

\begin{tabular}{|c|c|c|c|c|c|c|c|}
\hline \multirow[t]{2}{*}{ Hidra-Inf > } & Näo importante & & Razoavelmente importante & 3 & Muito importante & 9 & 12 \\
\hline & $\%$ & 0 & & 25 & & 75 & 100 \\
\hline \multirow[t]{3}{*}{ Inf-Hidra > } & Nẫo importante & & Razoavelmente importante & 5 & Muito importante & 12 & 17 \\
\hline & $\%$ & 0 & & 29 & & 71 & 100 \\
\hline & Média & 0 & & 27 & & 73 & 100 \\
\hline
\end{tabular}

Em média nas 2 turmas, $27 \%$ dos alunos disseram que o simulador foi razoavelmente importante, como ferramenta de apoio, e $73 \%$ afirmaram que é muito importante o uso deste tipo de simulador, tendo sido pouco significativa a diferença entre as turmas.

Tabela 2. Importância do uso dos simuladores

\begin{tabular}{|c|c|c|c|c|c|c|c|}
\hline & & & & & & & \\
\hline \multirow{2}{*}{ Hidra-Inf > } & Não importante & & Razoavelmente importante & $\overline{4}$ & Muito importante & 8 & 12 \\
\hline & $\%$ & 0 & & 33 & & 67 & 100 \\
\hline \multirow[t]{3}{*}{ Inf-Hidra > } & Não importante & & Razoavelmente importante & 3 & Muito importante & 14 & 17 \\
\hline & $\%$ & 0 & & 18 & & 82 & 100 \\
\hline & Média & 0 & & 25 & & 75 & 100 \\
\hline
\end{tabular}

Em média nas 2 turmas, $25 \%$ dos alunos disseram que utilizar recurso multimídia como o simulador, é razoavelmente importante, porém $75 \%$ dos alunos acharam muito importante.

Tabela 3. Importância do uso de tecnologias diversas Quão importante é o uso de tecnologias diversas, como apoio ao seu processo de aprendizagem?

\begin{tabular}{|c|c|c|c|c|c|c|c|}
\hline Hidra-Inf > & Não importante & & Razoavelmente importante & 1 & Muito importante & 11 & 12 \\
\hline & $\%$ & 0 & & 8 & & 92 & 100 \\
\hline \multirow[t]{3}{*}{ Inf-Hidra > } & Nã̀o importante & & Razoavelmente importante & 2 & Muito importante & 15 & 17 \\
\hline & $\%$ & 0 & & 12 & & 88 & 100 \\
\hline & Média & 0 & & 10 & & 90 & 100 \\
\hline
\end{tabular}

Em média nas 2 turmas, $90 \%$ dos alunos disseram ser muito importante o uso de tecnologias diversas, como apoio ao processo de aprendizagem, e $10 \%$ afirmaram ter sido razoavelmente importante.

Tabela 4. Quantificação do aprendizado com os simuladores

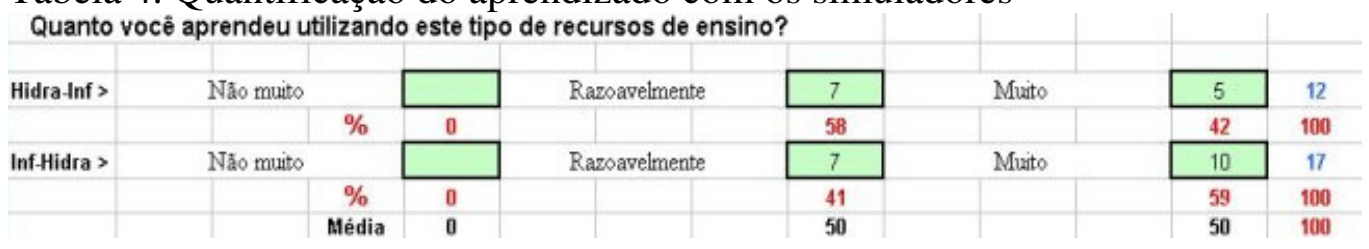




\begin{tabular}{|c|c|c|c|c|c|c|c|}
\hline \multicolumn{8}{|c|}{ Comparado a uma "prática tradicional ", quanto você aprendeu? } \\
\hline \multirow{2}{*}{ tidra-Inf > } & Muito menos & & Praticamente o mesmo & 5 & Muito mais & 7 & 12 \\
\hline & $\%$ & 0 & & 42 & & 58 & 100 \\
\hline \multirow[t]{3}{*}{ nf-Hidra > } & Muato menos & & Praticamente o mesmo & 8 & \multirow[t]{2}{*}{ Muito mais } & 9 & 17 \\
\hline & $\%$ & 0 & & 47 & & 53 & 100 \\
\hline & Média & 0 & & 44 & & 56 & 100 \\
\hline
\end{tabular}

Em média nas 2 turmas, 50\% dos alunos disseram terem aprendido muito com as simulações, enquanto que 50\% informaram que aprenderam praticamente o mesmo, sendo que quando questionados em relação à prática tradicional, 56\% disseram ter aprendido muito mais com as simulações, e $44 \%$ informaram que aprenderam praticamente o mesmo.

Tabela 5. Nível de satisfação no aprendizado Quanto você gostou deste recurso de simulação, introduzido nas aulas laboratoriais?

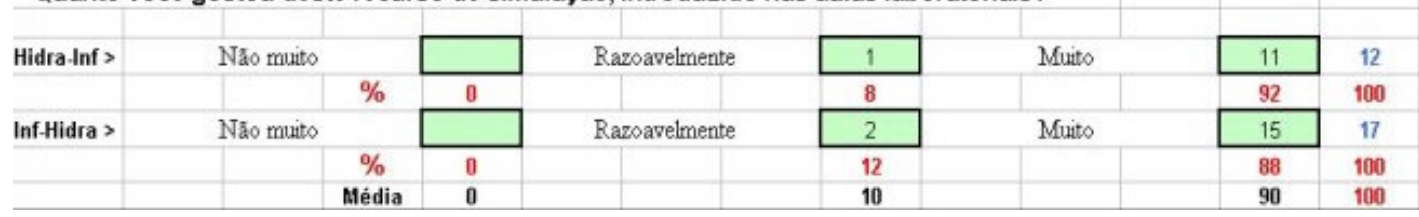

Em média nas 2 turmas, $90 \%$ dos alunos disseram ter gostado muito das simulações, e somente $10 \%$, afirmaram ter gostado razoavelmente.

Tabela 6. Comparação entre emprego de simulações e prática tradicional Comparado a uma " disciplina tradicional ", quanto você valorizaria uma disciplina que explora novas tecnologias e recursos de simulação no aprendizado?

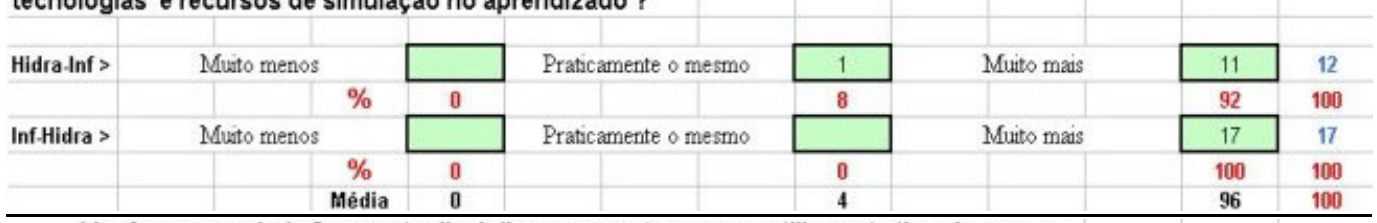

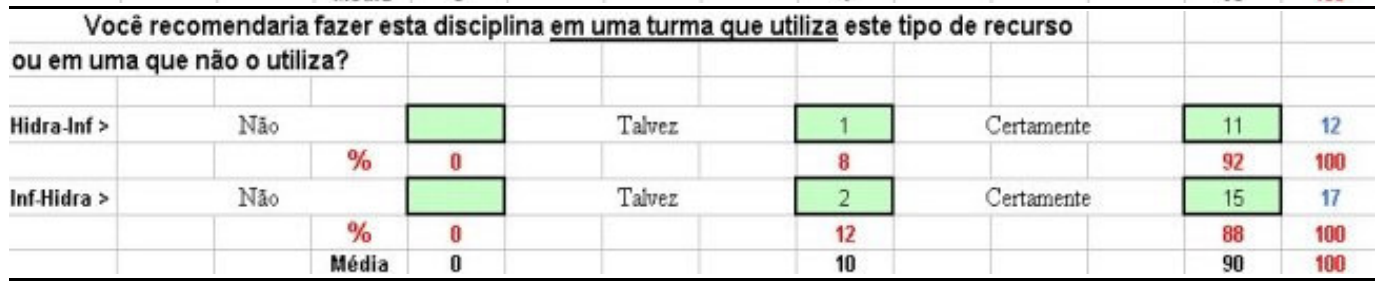

Em média nas 2 turmas, 96\% dos alunos disseram valorizar muito mais, uma disciplina que explora novas tecnologias de ensino, e tão somente $4 \%$ dos alunos, manifestaram que valorizam praticamente o mesmo, uma disciplina "tradicional" do que uma que usa novos recursos multimídia para a aprendizagem, destacando que $100 \%$ da turma que realizou primeiramente as simulações, valorizou muito mais uma disciplina mais "progressista". Ao mesmo tempo, 90\% da turma em média, manifestou que certamente recomendaria fazer uma disciplina, que utilizasse recursos como as simulações.

Tabela 7. Recomendação para aperfeiçoamento e uso de simuladores

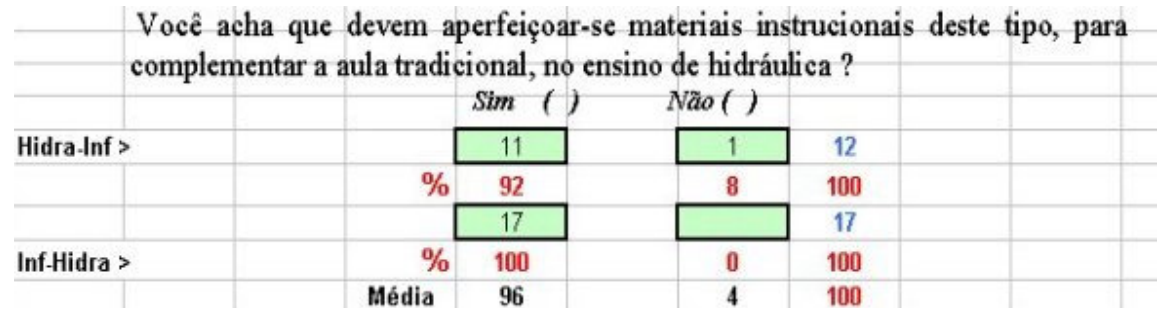


Quando questionados os alunos, quanto a se deviam aperfeiçoar-se materiais instrucionais deste tipo, para complementar a aula de hidráulica, em média $96 \%$ dos alunos disseram que precisa-se elaborar mais materiais deste tipo, sendo que $4 \%$ (representando um único aluno) disse que não vê necessidade de elaborar matérias de apoio multimídia.

Tabela 8. Papel da simulação no ensino de hidráulica

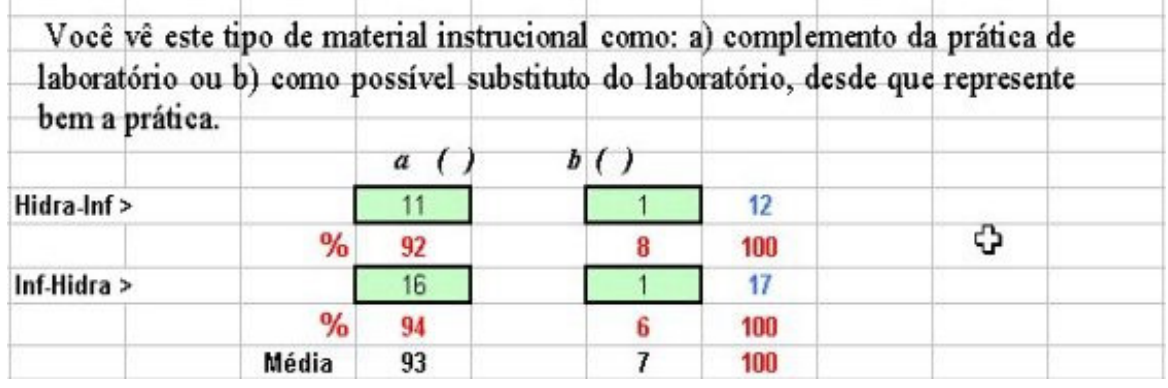

Por fim, quando os alunos foram questionados sobre a visão deles, a respeito da utilidade do novo material instrucional, em média 93\% dos alunos, manifestaram que as simulações servem como complemento das práticas de laboratório, e $7 \%$ em média disseram que as simulações podem ser possíveis substitutos das práticas.

\section{CONCLUSÃO}

O estudo de caso aqui apresentado demonstrou que as simulações são um ótimo complemento das aulas laboratoriais de hidráulica, permitindo aos alunos efetuarem os experimentos repetidamente, inclusive em suas residências, refletindo mais e melhor sobre os fenômenos investigados. Além disso, o ambiente dentro da sala de aula informatizada, foi muito propício e aberto para a discussão e debate sobre as inovações tecnológicas no ensino, principalmente pela postura dos alunos perante a utilização das simulações.

De maneira geral, toda a turma mostrou-se receptiva às simulações, com melhor aproveitamento por parte da turma Inf-Hidra. No entanto, não é possível afirmar, com os resultados até aqui levantados, se a ordem ideal é realizar antes as simulações do que a prática convencional. Novas experiências e avaliação de questionários com novas turmas talvez possam indicar este caminho. Na continuidade deste processo deverá ser analisada a receptividade de várias turmas a estas ferramentas, o que poderá permitir confirmações e conclusões mais abrangentes sobre o efeito que as simulações têm sobre o processo de ensino-aprendizagem dos alunos da Engenharia; no primeiro semestre de 2005 uma nova turma de graduandos da Engenharia realizou as simulações, porém os dados obtidos estão ainda sendo analisados.

Para a elaboração das simulações deverá existir uma equipe multidisciplinar abrangendo a área técnica do assunto em questão, a área pedagógica educacional e a área técnica da linguagem de desenvolvimento da simulação, em um ambiente de interação e colaboração entre os envolvidos.

Por fim deve-se ressaltar que, além de servir como um ótimo material de apoio ou complemento da aula prática, para aquelas Instituições que dispõem de recursos laboratoriais, o uso das simulações poderá ser também, excelente para aquelas Instituições que não dispõem destes recursos. A utilização das simulações em aulas práticas informatizadas, seria uma primeira aproximação para os alunos na avaliação 
dos fenômenos físicos estudados, contribuindo de maneira significativa para a qualidade do ensino como um todo.

\section{REFERÊNCIAS BIBLIOGRÁFICAS}

CAMAÑO SCHETTINI, Edith Beatriz. Desafios para o ensino e pesquisa em hidráulica. In: SIMPÓSIO BRASILEIRO DE RECURSOS HÍDRICOS, 15., 2003, Curitiba. Anais. Curitiba: ABRH, 2003. T606.

EDWARD, N. An evaluation of student perceptions of screen presentations in computer-based laboratory simulations. European Journal of Engineering Education, Oxfordshire, v. 22, n. 2, p. 143-151, June, 1997.

EDWARD, Norrie S. Evaluation of computer based laboratory simulation. Computers \& Education, New York, v.26, n.1/3, p.123-130, 1996.

EHRLICH, Pierre Jacques. Pesquisa operacional: curso introdutório. $5^{\circ}$ ed. São Paulo: Atlas, 1976. 189 p.

GORRELL, Jeffrey; CUEVAS, Anthony; DOWING, Huxter. Computer simulations of classroom behavior problems. Computers \& Education, New York, v.12, n.2. p.283-287, 1988.

KENNEPOHL, Dietmar. Using computer simulations to supplement teaching laboratories in chemistry for distance delivery. Journal of Distance Education, v. 16.2, 2001. Disponível em: <http://cade.athabascau.ca/vol16.2/kennepohl.html >. Acesso em: 14 dez. 2004.

MATEUS, Caroline Melissa Kleinhappel; PALHARES, Juliana Barbosa; LUViZOTTO JÚNIOR, Edevar. Laboratório virtual de mecânica do fluidos. In: CONGRESSO LATINOAMERICANO DE HIDRÁULICA, 21., São Paulo. São Paulo: UNICAMP.

OTONI, Luis. Educação Tecnológica - O uso de Simuladores e as Estruturas Cognitivas. PGIE/UFRGS e CEFET-RS. Disponível em: http://cmi.cefetrs.tche.br/ ribeiro/teste.htm - Acessado em 29/12/2004

TOVAL, Ambrosio; FLORES, Mariano. Computer systems simulation in education: description of an experience. Computers \& Education, New York, v.2, n.4, p.293-303, 1987.

VANCE, Shem; BOSWORTH, April. Replicating reality: the power of simulations. Salt Lake City, c2003. Disponível em: $<$ http://www.allencomm.com/webminars/moreinfo.aspx?CourseID=8>. Acesso em: 12 nov. 2004. 